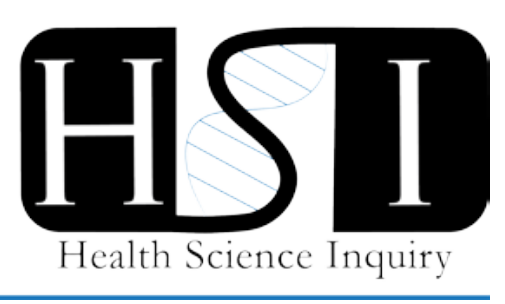

\title{
Food and beverage marketing: content not suitable for children
}

Kristen Reilly, Katherine Goren

Faculty of Health Sciences, University of Western Ontario

Childhood obesity affects 1 in 7 Canadian children, making it a national public health concern [1]. It is a multifactorial disease that can be attributed to environmental, hereditary, lifestyle, cultural, and social factors [2]. Childhood obesity acts as a precursor to obesity in adulthood, and increases the risk of additional chronic illnesses, such as type 2 diabetes, cardiovascular disease, metabolic syndrome, and cancer [2]. Furthermore, childhood obesity is associated with a reduced quality of life and can substantially impact a child's psychosocial wellbeing [3]. One significant, though often overlooked, contributor to childhood obesity is food and beverage marketing, which within the last half century, has emerged and proliferated into a multi-billion dollar industry in Canada [4].

Children are exposed to hundreds of advertisements per day, $90 \%$ of which promote unhealthy products (i.e., calorie-dense, low-nutrient, and high in salt, sugar and fat [4]. The reason for why food and beverage marketing is so detrimental to child health is that exposure to advertisements directly influences food preferences, choices, and eating habits among children [4,5]. In 2016, a meta-analysis by Canadian researchers demonstrated that exposure to unhealthy dietary marketing significantly increased the consumption of, and the preference for, unhealthy food and beverage products in children [5]. Despite the surmounting evidence of the negative implications associated with marketing food and beverage products to children, the practice is becoming more pervasive and the tactics are becoming increasingly extreme. Children are being inundated with food and beverage advertisements across numerous media and technology platforms, including, but not limited to television, websites, online games, video games, smartphone applications, and social media [4]. Less overtly, but still impactful, marketing of food and beverage products also occurs through product placement, celebrity endorsements, and corporate sponsorships of school and recreational events $[4,6]$.

It is not a coincidence that food and beverage companies are focusing specifically on children; in fact, marketers have identified this age demographic as the ideal target for reasons related to their buying and spending power, accessibility, and susceptibility to persuasive messaging [4]. In Canada, children not only have their own money to spend, but also have significant influence over their parents' purchases. In 2006, Canadian children aged 914 spent nearly $\$ 3$ billion, and in 2004 , were estimated to have determined $\$ 20$ billion of their parents' spending $[6,7]]$. As noted above, children are exposed to numerous sources of advertising, many of which are screen-based. The average Canadian child spends approximately 8 hours per day in front of screens, making them extremely accessible targets for marketing [4]. Finally, children are viewed as impulsive and impressionable consumers who lack the critical thinking skills necessary to comprehend the persuasive language and marketing techniques used in advertisements [4,6]. Until now, the food and beverage industry has largely self-regulated the marketing of its products to children; however, their efforts have been minimal and ineffectual. In 2007, The Canadian Children's Food and Beverage Advertising Initiative (CAI), was implemented with the overall purpose of reducing advertising to children under the age of 12 , and improving the nutritional quality of products targeted to them [8]. Though this initiative was promising in principle, it has failed in reality, largely due to the fact that participation of companies is voluntary, and that those involved can be selective about the criteria that they adhere to $[4,8]$. Interestingly, a recent report by the Heart and Stroke Foundation demonstrated that approximately $75 \%$ of the unhealthy advertisements viewed by children are, in fact, from companies that are members of the CAI $[4,8]$.

The legislation of policy has been proposed as a viable option for restricting food and beverage companies from marketing to children $[4,6,9]$. Policies of this nature have proven to be effective in reducing unhealthy behaviours and improving health outcomes in the past. For example, in 1980, Quebec pioneered legislation to ban all commercial advertising of goods and services to all persons under the age of 13 . Since then, the province has reported a $13 \%$ reduction in fast food purchases, as well as the lowest rate of obesity in any province in Canada $[4,10]$. The recently proposed Canadian Bill S-228 (i.e., Child Health Protection Act) would amend the current Food and Drugs 
Act to prohibit food and beverage marketing directed at persons under 17 years of age, and would include packaging, advertising, and other forms of promotion [9]. Bill S-228 is a stride in the right direction for health promotion in Canada. The marketing of unhealthy food and beverage products is an exploitive industry that puts children at risk for a myriad of chronic health conditions. Institution of Bill S-228 would not only terminate the predatory and unethical marketing practices of food and beverage companies, but would also support children in making healthy choices about food, potentially lowering national rates of childhood obesity. Researchers, health professionals, policymakers, and parents must continue to advocate for the protection of children and demand accountability from the industry for putting them in harm's way.

\section{References}

[1] Rao, D. P., Kropac, E., Do, M. T., Roberts, K. C., Jayaraman, G. C. (2014) Childhood Overweight and Obesity Trends. Heal Promot, 36 (9), 1948. Available from: http://www.ncsl.org/research/health/childhoodobesity-trends-state-rates.aspx

[2] Biro, F. M., Wien, M. (2010) Childhood obesity and adult morbidities 14. Am J Clin Nutr, 91 (1), 14991505. Available from: https://www.ncbi.nlm.nih.gov/pmc/articles/PMC2854 915/pdf/ajen9151499S.pdf

[3] Pulgarón., E. R. (2013) Childhood obesity: a review of increased risk for physical and psychological comorbidities. Clin Ther, 35 (1), A18-32. Available from: http://www.ncbi.nlm.nih.gov/pubmed/23328273.
[4] Lawrence, S. (2017) The kids are not alright. How the food and beverage industry is marketing our children and youth to death. In: 2017 Report on the Health of Canadians, Heart and Stroke Foundation of Canada.

[5] Sadeghirad, B., Duhaney, T., Motaghipisheh, S., Campbell, N. R. C., Johnston, B. C. (2016) Influence of unhealthy food and beverage marketing on children's dietary intake and preference: a systematic review and meta-analysis of randomized trials. Obes Rev, 17 (10), 94559.

[6] Nadeau, M-E. (2011) Food Advertising Directed at Children: Review of Effects, Strategies, and Tactis. Coalit Poids, 2011, 145.

[7] Food and Beverage Marketing to Kids - Why are Children the target? Stop Marketing to Kids Coalition. Available from: http://stopmarketingtokids.ca/what-ismarketing/

[8] Canadian Children's Food and Beverage Advertising Initiative. Advertising Standards Canada, 2018. Available from: http://www.adstandards.com/en/childrensinitiative/ab out.html

[9] Bill S-228 An Act to amend the Food and Drugs Act (prohibiting food and beverage marketing directed at children). Parliament of Canada, 2017. Available from: https://www.parl.ca/LegisInfo/BillDetails.aspx?billld= 8439397\& Language $=\mathrm{E}$

[10] Dhar, T., Baylis, K. (2011) Fast-Food Consumption and the Ban on advertising Targeting Children: The Quebec Experience. J Mark Res, 48 (5), 799813. 


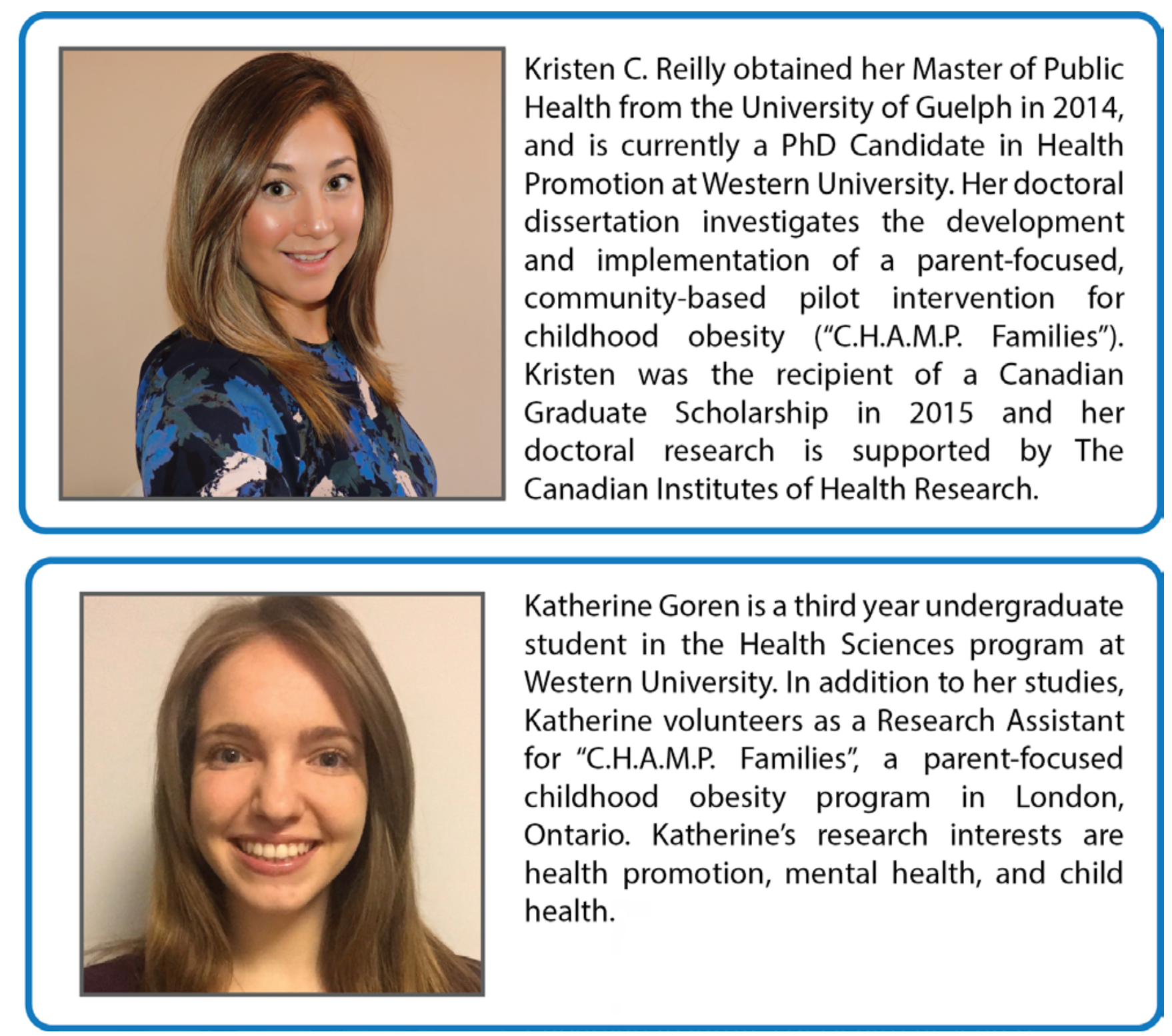

